\title{
Development of a Redox-Free Mitsunobu Reaction Exploiting Phosphine Oxides as Precursors to Dioxyphosphoranes
}

\section{Xiaoping Tang, ${ }^{a}$ Charlotte Chapman, ${ }^{a}$ Matthew Whiting, ${ }^{, b}$ and Ross Denton ${ }^{a *}$}

The development of the first redox-free protocol for the Mitsunobu reaction is described. This has been achieved by

5 exploiting triphenylphosphine oxide - the unwanted by-product in the conventional Mitsunobu reaction - as the precursor to the active $P(V)$ coupling reagent. Multinuclear NMR studies are consistent with hydroxyl activation via an alkoxyphosphonium salt.

Bimolecluar nucleophilic substitution reactions of alcohols are fundamentally important transformations in chemical synthesis. During the last sixty years phosphorus $(\mathrm{V})$ compounds have emerged as widely used activating agents for nucleophilic coupling

10 reactions through a process originally described by Mukaiyama as "redox dehydration". ${ }^{1}$ The most familiar of these protocols being the 1967 Mitsunobu reaction² (Scheme 1).

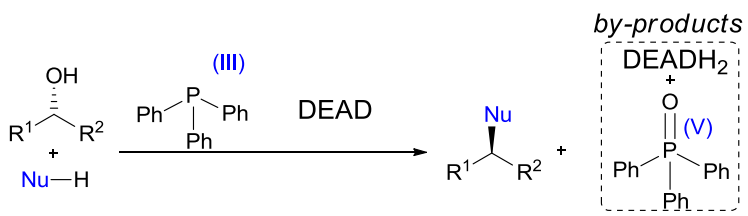

Scheme 1 The 1967 Mitsunobu protocol based on the $\mathrm{DEAD} / \mathrm{PPh}_{3}$ combination

Although this powerful protocol has been widely employed in chemical synthesis it suffers from low atom economy. 15 Furthermore, the diazodicarboxylate oxidants are toxic, high energy compounds and the derived hydrazine and phosphine oxide by-products can complicate product isolation. To this end many creative strategies have been developed to aid purification. For example, tagged ${ }^{3}$ or polymeric phosphine and diazodicarboxylate reagents have emerged. Notable work in this area includes bipyridyl-tagged phosphine reagents, ${ }^{4}$ fluorous phosphines, ${ }^{5}$ tetraaryl phosphonium salts incorporating phosphines, ${ }^{6}$ Rasta Resins, ${ }^{7}$ a "waste as catalyst strategy" ${ }^{8}$ and "impurity annihilation" methods. ${ }^{9}$

20 More recently the requirement for both a stoichiometric oxidant and phosphine in the Mitsunobu coupling and other phosphorus-mediated reactions has begun to be addressed. ${ }^{10}$ In a pioneering study, Toy described a Mitsunobu system that employed substoichiometric DEAD and an iodine(III)-based terminal oxidant. ${ }^{11}$ More recently still Taniguchi has demonstrated an impressive catalytic variant that exploits molecular oxygen as the terminal oxidant. ${ }^{12}$ The necessity for an oxidant in the Mitsunobu procedure is a consequence of the fact that phosphorus $(\mathrm{V})$ reagents have been accessed almost exclusively in an

25 oxidative sense from phosphine precursors e.g. triphenylphopshine and DEAD (Scheme 1). A corollary of this conventional approach is that any phosphorus recycling or indeed catalysis ${ }^{13,14}$ of such reactions must be achieved through the addition of a terminal reductant. ${ }^{15}$

In contemplating a method to improve the Mitsunobu reaction and eliminate hydrazine by-products we were attracted to a conceptually distinct alternative in which the active phosphorus $(\mathrm{V})$ reagent would be accessed from a phosphorus $(\mathrm{V})$ 30 precursor, ${ }^{16}$ specifically triphenylphosphine oxide - the unwanted by-product from the redox-based protocol (Scheme 2). ${ }^{17}$

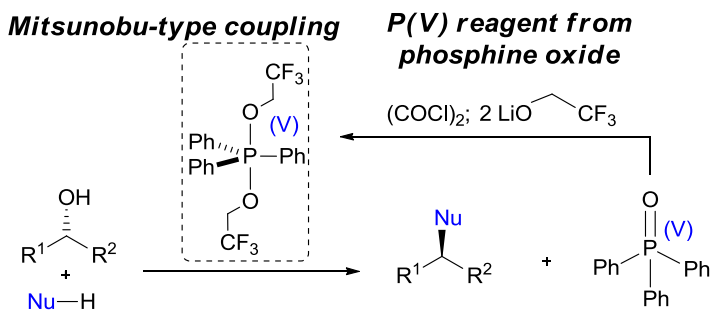

Scheme 2 This work: a redox-free Mitsunobu process which relies upon generation of the active $\mathrm{P}(\mathrm{V})$ reagent from triphenylphosphine oxide.

Such a protocol was attractive since it would: (a) eliminate the need for an oxidant; (b) eliminate competing side reactions 35 such as alkylation of the hydrazinedicarboxylate; and (c) result in no net phosphorus waste. To the best of our knowledge this approach has only been investigated to date by Jenkins, whose detailed studies on the Hendrickson reagent $\left(\mathrm{Ph}_{3} \mathrm{POPPh}_{3} \cdot 2 \mathrm{OTf}\right)$ indicated that the latter could function in analogy to the Mitsunobu system for esterification of primary alcohols. However, critically, in the case of secondary alcohols the ester products were obtained with retention of configuration ${ }^{18}$

40 In this communication we describe the successful implementation of redox-free Mitsunobu inversion reactions in which the active phosphorus $(\mathrm{V})$ reagent is obtained from triphenylphosphine oxide.

The approach taken (Scheme 2) was contingent upon accessing the required dioxyphosphorane - of which many are 
known 19,20,21,22 - from triphenylphosphine oxide. While this was unprecedented at the time of our study we reasoned that the established conversion of phosphine oxides into chlorophosphonium salts ${ }^{23}, 24$ would provide a means to access the required dioxyphosphoranes following addition of the appropriate alkoxides. Gratifying this proved to be the case and several dioxyphosphoranes ${ }^{25}$ were obtained through this protocol (Scheme 3 ) including dioxyphosphorane $3\left({ }^{31} \mathrm{P} \delta=-58.2,{ }^{2} \mathrm{~J}_{\mathrm{C}-\mathrm{P}} \mathrm{J}=6.0\right.$, $5{ }^{19} \mathrm{~F} \delta=-74.3,{ }^{2} J_{F-F}, J=9.0 \mathrm{CDCl}_{3}$ ), which was originally described by Ishikawa and is known to promote a wide range of Mitsunobu-type coupling reactions. ${ }^{22}$

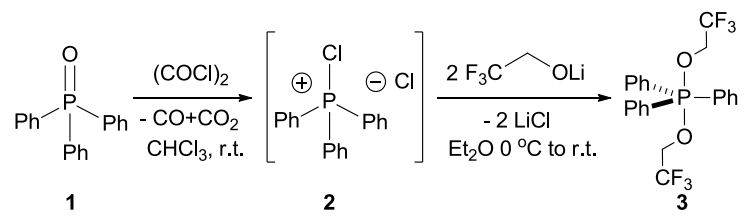

Scheme 3 Synthesis of the Ishikawa phosphorane $\mathbf{3}$ from triphenylphosphine oxide.

While these studies were instructive and guided our choice of phosphorane the stereochemical outcome of intermolecular 10 coupling reactions using 3 remained unknown. ${ }^{26}$ A further attractive feature of 3 was the presence of the $\mathrm{CF}_{3}$ groups which allowed us to calculate the molarity of stock solutions of the reagent using ${ }^{19} \mathrm{~F} \mathrm{NMR} .{ }^{27}$

Having developed a new method to access the Ishikawa dioxyphosphorane we next developed a Mitsunobu-type alcohol inversion protocol using reagent $\mathbf{3}$ and ethyl acetate as solvent (Table 1).

The redox-free coupling reactions took place with inversion of configuration with both non-activated (entries 1 and 2 ) as well 15 as an activated secondary alcohol (entry 3 and 4). The process depicted in entry 1 was equally efficient on 15 mmol scale (with respect to the alcohol) and, in this case, $86 \%$ of triphenylphosphine oxide was recovered for reuse in subsequent coupling reactions. Furthermore, we determined that the stereochemical outcome of the reaction was independent of the order of addition of the alcohol and carboxylic acid.

Additional secondary alcohols underwent esterification in good yield (entries 5 and 6). Acetic acid could also be employed

20 in place of the aromatic carboxylic acids (entry 9); however, the isolated yield in this case was moderate. Finally, menthol underwent esterification with inversion of configuration albeit in low yield (entries 10 and 11).

With this protocol in hand we carried out a multinuclear NMR study in order to gain further insight into the course of the reaction. We were particularly interested in establishing whether or exchange of one of the trifluoroalkoxy ligands at phosphorus would occur in the presence of the alcohol alone to generate a mixed dioxyphosphorane of general structure

$25 \mathrm{Ph}_{3} \mathrm{P}\left(\mathrm{OCH}_{2} \mathrm{CF}_{3}\right)(\mathrm{OR})$ as originally proposed by Ishikawa.

The results we obtained (Scheme 4 ) indicated that this was not the case with (S)-2-octanol. Thus a $0.25 \mathrm{M}$ solution of 3 in ethyl acetate remained unchanged upon addition of one equivalent of the alcohol. However, upon addition of benzoic acid the ${ }^{31} \mathrm{P}$ resonance at $-59.6 \mathrm{ppm}$ was replaced by a new signal at $53.4 \mathrm{ppm}$ which corresponds to the indicated alkoxyphosphonium salt with a carboxylate counteranion. The structure of this intermediate is corroborated by the presence of a single peak in the

$30{ }^{19} \mathrm{~F}$ NMR, which corresponds to trifluoroethanol and rules out the formation of a "mixed" dioxyphosphorane of the type $\mathrm{Ph}_{3} \mathrm{P}\left(\mathrm{OCH}_{2} \mathrm{CF}_{3}\right)(\mathrm{OR})$. The former species then underwent slow Arbuzov collapse to the afford ester product with inversion of configuration with concomitant generation of triphenylphosphine oxide. 
Table 1 Redox-free Mitsunobu reactions using phosphorane 3 . $^{\text {a }}$

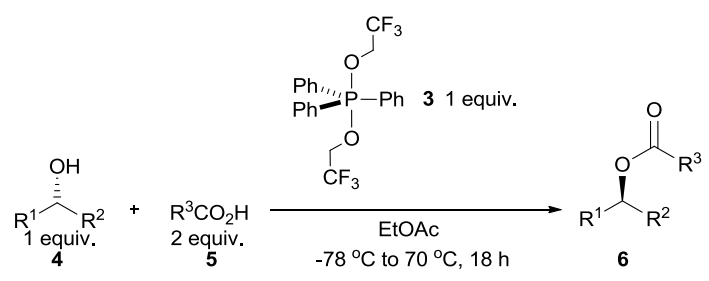

Entry Product $\begin{aligned} & \text { Yield } \\ & \text { e.e. }\end{aligned}$ Entry Product

3

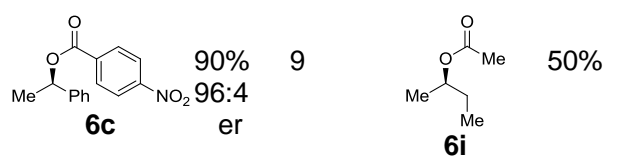

4<smiles>O=C(OC(c1ccccc1)c1ccccc1)c1ccccc1</smiles>

5<smiles>O=C(OC1CCN([18OH])C1)c1ccccc1</smiles>

10

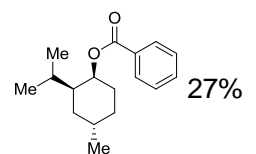

11

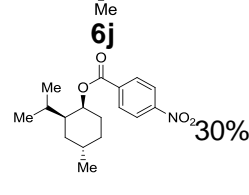

$6 k$

6

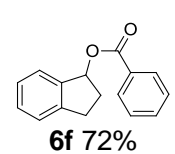

${ }^{a}$ For each entry the isolated yield after chromatography is reported.

\section{Conclusions}

5 In summary we have developed for the first time a redox-free approach to Mitsunobu inversion reactions that relies upon accessing the Ishikawa phosphorane $\mathbf{3}$ from triphenylphosphine oxide.

This new protocol eliminates the need for diazo-based oxidants and, given that reagent $\mathbf{3}$ is also known to promote $\mathrm{C}-\mathrm{N}$, C$\mathrm{S}$ and other cyclodehydration reactions, ${ }^{22}$ opens up a wide range of other useful Mitsunobu-type reactions that will not require the addition of an external oxidant. Furthermore, since triphenylphosphine oxide is used to prepare the coupling reagent no 10 net phosphorus waste is generated. 

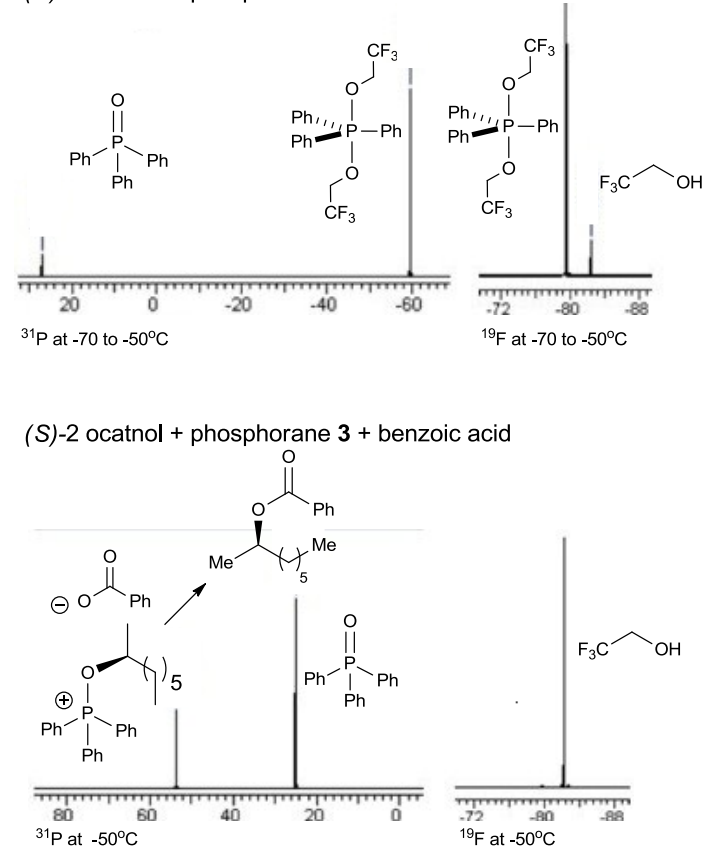

Scheme 4 Multinuclear NMR study

\section{Notes and references}

${ }^{a}$ School of Chemistry, University Park, University of Nottingham, Nottingham, United Kingdom. Tel: 441159514194; E-mail:

5 ross.denton@nottingham.ac.uk

${ }^{b}$ GlaxoSmithKline, Gunnels Wood Road, Stevenage, United Kingdon.

† Electronic Supplementary Information (ESI) available: [details of Mitsunobu coupling procedure and full experimental supporting information]. See DOI: 10.1039/b000000x/

10

1 (a) T. Mukaiyama, I. Kuwajima and Z. Suzuki, J. Org. Chem. 1963, 28, 2024; for review, see (b) T. Mukaiyama, Angew. Chem. Int. Ed. 2004, 43, 5590 .

2 (a) O. Mistunobu, and M. Yamada, Bull. Chem. Soc. Jpn. 1967, 40, 2380; (b) O. Mitsunobu, and M. Eguchi, Bull. Chem. Soc. Jpn. 1971, 44, 3427; for reviews, see (c) O. Mitsunobu Synthesis 1981, 1; (d) D.L. Hughes in Organic Reactions, Vol. 42 (Ed.: L.A. Paquette), Wiley, New York, 1992, p. 335; (e) K.C.K. Swamy, N.N.B. Kumar, E. Balaraman and K.V.P.P. Kumar, Chem. Rev. 2009, 109, 2551; (f) D.L. Hughes Org. React. 1992, 42, 335; (f) D.L. Hughes, Org. Prep. Proced. Int. 1996, 28, 127; (g) R. Dembinski, Eur. J. Org. Chem. 2004, 2763;

(h) T.Y.S. But, P.H. Toy Chem. Asian J. 2007, 2, 1340.

${ }^{3}$ For a review on lesser-known enabling technologies in synthesis, including tagged reagents and phase switching, see M. O'Brien, R.M. Denton and S.V. Ley, Synthesis 2011, 8, 1157.

4 C.D. Smith, I.R. Baxendale, G.K. Tranmer, M. Bauman, S.C. Smith, R.A. Lewthwaite and S.V. Ley, Org. Biomol. Chem., $2007,5,1562$.

5 (a) S. Dandapani and D. P. Curran, Tetrahedron, 2002, 58, 3855; for a review on the use of fluorous reagents, see (b) D.P. Curran, Angew. Chem. Int. Ed. 1998, 37, 1174; for a more recent review, see (c) A.P. Dobbs and M.R. Kimberly, Journal of Fluorine Chemistry 2002, 118, 3.

${ }^{6}$ J.-C. Poupon, A. A. Boezio, A. B. Charette, Angew. Chem. Int. Ed. 2006, 45, 1415.

${ }^{7}$ P. S.-W. Leung, Y. Teng and P. H. Toy, Synlett, 2010, 1997.

${ }^{8}$ J.-J. Cao, F. Zhou and J. Zhou Angew. Chem. Int. Ed. 2010, 49, 4976.

${ }^{9}$ A.G. M. Barrett, R.S. Roberts and J. Schröder, Org. Lett., 2000, 2, 2999.

${ }^{10}$ For example, Lambert has reported a cyclopropenone-catalysed alcohol inversion protocol, see: E.D. Nacsa and T.H. Lambert Org. Lett. 2013, 15, 38; a catalytic chlorination reaction has also been developed, see: C.M. Vanos and T.H. Lambert Angew. Chem. Int. Ed. 2011, 52, 4524.

${ }^{11}$ (a) T.Y.S. But and P.H. Toy, J. Am. Chem. Soc. 2006, 128, 9636; (b) T.Y.S. But, J. Lu, P.H. Toy, Synlett 2010, 1115.

${ }^{12}$ D. Hirose, T. Taniguchi and H. Ishibashi, Angew. Chem. Int. Ed. 2013, 52, 4613.

${ }^{13}$ For a review on catalytic variants of phosphorus(V)-mediated reactions, see S.P. Marsden in Sustainable Catalysis: Challenges and Practices for the Pharmaceutical and Fine Chemical Industries (Ed.: P.J. Dunn and K.K. Hii, Wiley, New York, 2013, p339.

${ }^{14}$ A range of catalytic phosphorous-based reactions have been achieved using silane-mediated reductive turnover, see: (a) C.J. O'Brien, J.L. Tellez, Z.S. Nixon, L.J. Kang, A.L. Carter, S.R. Kunkel, K.C. Przeworski, and C.G. Chass, Angew. Chem. Int. Ed. 2009, 48, 6836; (b) H.A. van Kalkeren, S.H.A.M. 
Leenders, C.R.A. Hommersom, F.P.J.T. Rutjes and F.L. van Delft, Chem. Eur. J. 2011, 17, 11290; (c) H.A. van Kalkeren, J.J. Bruins, F.P.J.T. Rutjes, and F.L. van Delft, Adv. Synth. Catal. 2012, 354, 1417; (d) A.D. Kosal, E.E. Wilson and B.L. Ashfeld, Angew. Chem. Int. Ed. 2012, 124, 12202; (e) J.R. Harris, M.T. Haynes II, A.M. Thomas and K.A. Woerpel, J. Org. Chem. 2010, 75, 5083; (f) H.A. van Kalkeren, C. Te Grotenhuis, F.S. Haasjes, C.A. Hommersom, F.P.J.T. Rutjes and F. L. van Delft, Eur. J. Org. Chem. 2013, 7059; (g) C.J. O'Brien, Z.S. Nixon, A.J. Holohan, S.R. Kunkel, J.L. Tellez, B.J. Doonan, E.E. Coyle, F. Lavinge, L.J. Kang and K.C. Przeworski; (h) C.J. O’Brien, F. Lavinge, E.E. Coyle, A.J. Holohan and B.J. Doonan, Chem. Eur. J. 2013, 19, 5854.

${ }^{15}$ For two recent approaches to silane-based catalytic phosphine oxide reduction, see (a) Y. Li, S. Das, S. Zhou, K. Junge and M. Beller, J. Am. Chem. Soc. 2012, 134, 9727; (b) Y. Li, L.-Q. Lu, S. Das, S. Pisiewicz, K. Junge, M. Beller, J. Am. Chem. Soc. 2012, 134, 18325.

${ }^{16}$ The concept of redox-neutral phosphorus(V)-based reactions was first demonstrated by Marsden in the context of the first catalytic aza-Wittig reaction, see A.E. McGonagle, S.P. Marsden, and B. McKever-Abbas, Org. Lett. 2008, 10, 2589.

${ }^{17}$ We have also exploited this concept to develop a catalytic platform for Appel halogenations, see (a) (a) R.M. Denton, A. Jie, and B. Adeniran, Chem. Commun. 2010, 46, 3025; (b) R.M. Denton, X. Tang and A. Przeslak, Org. Lett. 2010, 12, 4678; (c) R.M. Denton, A. Jie, B. Adeniran, A. Blake, W. Lewis, and A. Poulton, J. Org. Chem. 2011, 76, 6749; (d) R.M. Denton, A. Jie, P. Lindovska, and W. Lewis, Tetrahedron, 2012, 68, 2899; (e) A. Jie, X. Tang, J. Moore, W. Lewis and R.M. Denton, Tetrahedron, 2013, 69, 8769. This stratey has also been used by Xu for catalytic 1,3-dichlorination reactions, see (f) T.-Y. Yu, Y. Wang and P.-F. Xu, Chem. Eur. J. 2014, 20, 98.

$\left.{ }^{18}\right]$ (a) H. Kunz and P. Schmidt, Chem. Ber. 1979, 112, 3886; (b) K. E. Elson, I.D. Jenkins and W. A. Loughlin, Org. Biomol. Chem. $2003,1,2958$.

${ }^{19}$ (a) F. Ramirez and N. B. Desai, J. Am. Chem. Soc., 1960, 82, 2652; (b) F. Ramirez and N. B. Desai, J. Am. Chem. Soc., 1963, 85, 3252; (c) Ramirez in "Organophosphorus Compounds," International Symposium, Heidelberg, 1964, IUPAC, Butterworth and Co., Ltd., London, 1964, pp 337-369; (d) F. Ramirez and N. Ramanathan, J. Org. Chem., 1961, 26, 3041; (e) F. Ramirez, N. Ramanathan, and N. B. Desai, J. Am. Chem. Soc., 1963, 85, 3465; (f) F. Ramirez, N. Ramanathan, and N. B. Desai, J. Am. Chem. Soc., 1962, 84, 1317; (g) F. Ramirez, A. V. Patwardhan, N. B. Desai, N. Ramanathan, and C. V. Greco, J. Am. Chem. Soc., 1963, 85, 3056; (h) F.Ramirez, A. V. Patwardhan, N. Ramanathan, N. B. Desai, C. V. Greco, and S. R. Heller, J. Am. Chem. Soc., 1965, 87, 549; (i) F. Ramirez, S. B. Bhatia, and C. P. Smith, Tetrahedron, 1967, 23, 2067; (j) F. Ramirez, S. B. Bhatia, A. V. Patwardhan, and C. P. Smith, J. Org. Chem., 1967, 32, 2194; (k) F. Ramirez, M. Nagabhushanam, and C. P. Smith, Tetrahedron, 1968, 24, 1785; for a review, see F. Ramirez, Acc. Chem. Res. 1968, 1, 168.

${ }^{20}$ (a) D.B. Denney and H.M. Relles, J. Am. Chem. Soc., 1964, 86, 3897; (b) D.B. Denney and S.T.D. Gough, J. Am. Chem. Soc., 1965, 87, 138; (c) D.B. Denney and D.H. Jones, J. Am. Chem. Soc., 1969, 91, 5821; (d) D.B. Denney, D.Z. Denney. B.C. Chang and K.L. Marsi, J. Am. Chem. Soc., 1969, 91, 5243; (e) B.C. Chang, W.E. Conrad, D.B. Denney, D.Z. Denney, R. Edelman, R.L. Powell and D.W. White, J. Am. Chem. Soc., 1971, 93, 4004; (f) D.B. Denney, D.Z. Denney, C.D. Hall and K.L. Marsi, J. Am. Chem. Soc., 1972, 94, 245; D.B. Denney, D.Z. Denney and J.J. Gigantino, J. Org. Chem., 1984, 49, 2831.

${ }^{21}$ (a) P.L. Robinson, C.N. Barry, J.W. Kelly and S.A. Evans, J. Am. Chem. Soc., 1985, 107, 5210; (b) P.L. Robinson, C.N. Barry, S.W. Bass, S.E. Jarvis and S.A. Evans, J. Org. Chem., 1983, 48, 5396; (c) J.W. Kelly and S.A. Evans, J. Am. Chem. Soc., 1986, 108, 7681; (d) W.T. Murray, J.W. Kelly and S.A. Evans, J. Org. Chem., 1987, 52, 525; (e) P.L. Robinson, J.W. Kelly and S.A. Evans, Phosphorus Sulfur 1987, 31, 59; (f) W.T. Murray and S.A. Evans, J. Org. Chem., 1989, 54, 2440; (g) A.M. Pautard and S.A. Evans, J. Org. Chem., 1988, 53, 2300; (h) A. Pautard-Cooper and S.A. Evans, J. Org. Chem., 1989, 54, 2485.

${ }^{22}$ T. Kubota, S. Miyashita, T. Kitaxume and N. Ishikawa, J. Org. Chem. 1980, 45, 50. The reagent was prepared oxidatively from $\mathrm{PPh}_{3}$ in this original study.

${ }^{23}$ (a) K. Hojo and T. Mukaiyama, Chem. Lett. 1976, 619; (b) T. Mukaiyama, S.I. Shoda, and Y. Watanabe, Chem. Lett. 1997, 383; (c) K.V. Rajendran and D.G. Gilheany, Chem. Commun. 2011, 48, 817; (d) K.V. Rajendran, and Gilheany, D.G. Chem. Commun. 2012, 48, 10040; (e) K.V. Rajendran, J.S. Kudavalli, K.S. Dunne and D.G. Gilheany, Eur. J. Org. Chem. 2012, 14, 2720; (f) P.A. Byrne, K.V. Rajendran, J. Muldoon, and D.G. Gilheany, Org. Biomol. Chem. 2012, 10, 3531; (g) K. Nikitin, M.-B. Helger and D.G. Gilheany Chem. Commun. 2013, 49, 1434.

${ }^{24}$ Halophosphonium salts e.g. chlorotriphenylphosphonium chloride and bromotriphenylphosphonium bromide are themselves known to promote a variety of deoxyhalogenation and dehydration reactions, see L. Horner, H. Oediger and H. Hoffmann, Liebigs Ann. Chem. 1959, 626, 26. These reactions constitute an alternative protocol to the more widely employed "Appel conditions" of triphenylphosphine and carbon tetrachloride.

25 See the supporting information for details of further dioxyphosphoranes which were prepared and characterised.

26 While the stereochemical outcome of the Mitsunobu $\mathrm{Ph}_{3} \mathrm{P} / \mathrm{DEAD}$ system is well known to proceed with inversion the stereochemical course of related coupling reactions that are mediated by dioxyphosphoranes is much less certain and can, depending on the identity of the phosphorus(V) reagent and solvent proceed with inversion or retention. For leading studies, see: (a) J. McNulty, A. Capretta, V. Laritchev, J. Dyck, A.J. Robertson, Angew. Chem. Int. Ed.2003, 42, 4041 .

27 For details refer to the supporting information. 